\title{
EL IMPERIO DE LA LEY \\ Y LA CRISIS DE LA LEY
}

\section{Introducción ${ }^{1}$}

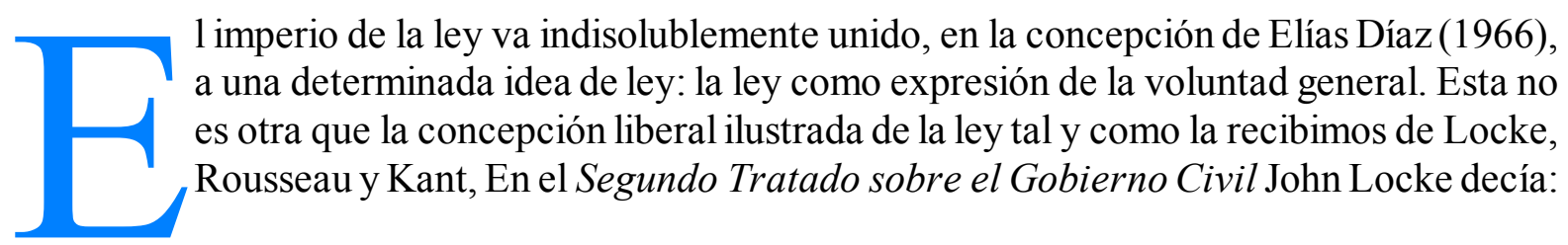

«Ningún edicto u ordenanza, sea de quien sea, esté redactado en la forma que lo esté y cualquiera que sea el poder que lo respalde, tienen la fuerza y el apremio de una ley, si no ha sido aprobada por el poder legislativo elegido y nombrado por el pueblo. Porque, sin esta aprobación, la ley no podría tener la condición absolutamente indispensable para que lo sea, a saber, el consenso de la sociedad, puesto que nadie existe por encima de ella con poder para hacer leyes, sino mediante su consentimiento y con la autoridad que esa sociedad le ha otorgado...» (Locke 1690, Capítulo XI, § 134).

Sabido es que, para Locke, este poder legislativo era supremo pero limitado, limitado tanto en su contenido (pues los hombres no podrían delegar en el legislativo aquellos poderes que ellos mismos no poseían en el estado de naturaleza) como en su forma (pues había de ser ejercido mediante leyes fijas y promulgadas), y era asimismo condicionado e indelegable. ${ }^{2}$

Más complicada es la concepción de la ley de Juan Jacobo Rousseau en cuanto «voluntad general» -general tanto por el sujeto como por el objeto ${ }^{3}$ - de la que nos ha quedado, sin embargo, la convicción generalizada de que la ley es expresión de la «voluntad general» o, lo que es lo mismo, la forma en que se manifiesta la soberanía que es «el ejercicio de la voluntad general» (Rousseau 1762, Libro Segundo, Capítulo 1); concepción ésta, por otra

\footnotetext{
${ }^{1}$ Este trabajo forma parte de un Proyecto de Investigación financiado por la DGICYT (n ${ }^{\circ}$ PB94-0193).

${ }^{2}$ Vid. Locke 1690, Capítulo XI, § 135 al 142.

${ }^{3}$ Vid. J. J. Rousseau 1762, Libro Segundo, Capítulo VI.
} 
parte, que permanece en Kant cuando atribuye el poder legislativo a la «voluntad unida del pueblo», la cual constituye al mismo tiempo el poder soberano hasta el punto de que «la soberanía se halla en las leyes» (González Vicén 1984, p. 51).

Esta era también la concepción generalmente aceptada en el pensamiento jurídico contemporáneo ${ }^{4}$. La cuestión que quiero suscitar se refiere a lo que algunos han llamado «la crisis actual de la ley», es decir de este preciso concepto de ley que, en efecto, parece estar puesto en cuestión por una serie de dinámicas tanto teóricas como prácticas que aparentemente tienden a socavar esta idea: la de que la ley es la expresión de la voluntad general y por ello, y sólo por ello, la expresión normativa suprema.

Antes de entrar en el análisis de esas dinámicas conviene repasar las consecuencias implícitas en esta concepción del imperio de la ley que, en palabras de Elías Díaz, constituye «la nota primaria y fundamental del Estado de Derecho» (Díaz 1966, p. 30). Cuando hablamos de «imperio de la ley» en este sentido nos referimos a un determinado valor o a su exigibilidad ética, nos situamos -como recientemente ha señalado Laporta- en un «universo ético» y formulamos «un complejo imperativo moral dirigido al sistema jurídico» (Laporta 1994, p. 134) cuyo fundamento último es el principio de la autonomía de la persona (ibíd., pp. 135-136) que deriva de la necesidad de asegurar la autonomía del sujeto individual en situaciones de dependencia estratégica, es decir de situaciones en que la autonomía de cada uno tiene que coexistir con la autonomía de los demás y -en ausencia de leyes- podría resultar limitadora de o limitada por la autonomía de los otros. Es precisamente ésta la forma en que Kant concebía la manifestación jurídica del imperativo categórico: la ley que hace posible el máximo de libertad de cada uno compatible con la libertad ajena ${ }^{5}$.

Esta idea del «imperio de la ley» como exigencia ética admite, sin embargo, dos interpretaciones, una débil y una fuerte. A la primera la denomino «interpretación débil» porque exige menos elementos cualificadores ya que prescinde de cuál sea el origen de la ley, limitando las exigencias del «imperio de la ley» a determinados criterios estructurales en la formulación y aplicación de las normas jurídicas. Esta es -me parece- la tesis que, entre otros, ha mantenido recientemente Francisco Laporta (ibíd., passim) ${ }^{6}$ al calificar

${ }^{4}$ Por todos, A. Pizzorusso, 1984, II, p. 231: «En el Estado liberal parlamentario, la ley del Parlamento (o «ley formal») constituía la expresión máxima de la voluntad del Estado, en cuanto manifestación que era de los representantes de la nación.»

\footnotetext{
${ }^{5}$ Una acción es conforme a Derecho cuando, según ella o según su máxima, la libertad del arbitrio de cada uno puede conciliarse con la libertad de todos, según una ley general... La ley jurídica general: obra externamente de tal modo que el libre ejercicio de tu arbitrio pueda conciliarse con la libertad de todos según una ley general...», E. Kant 1797 (1978, pp. 80-81).

${ }^{6}$ Me parece que la tesis «débil» está más cercana a la idea clásica del «rule of law» tal y como fue formulada por A. V. Dicey en su Introduction to the Study of the Law of the Constitution, de 1885.
} 
la posición de Elías Díaz como «amplia y ambiciosa» y proponer, en su lugar, una distinción entre el «imperio de la ley» y el «principio democrático» ${ }^{7}$, reduciendo el imperio de la ley a la existencia de un conjunto de normas que cancelen el ámbito de las decisiones arbitrarias, lo que requiere una cierta estructura de esas normas (competencia, generalidad, no retroactividad y publicidad) y un cierto procedimiento institucional de aplicación de ellas (el «due process of law»). Sin negar en absoluto la dimensión ética que esta tesis más débil implica, creo por mi parte que una «interpretación fuerte», como lo es la de Elías Díaz, que introduce en la noción misma de «imperio de la ley» el elemento democrático, resulta necesaria, bajo ese mismo punto de vista ético, para dotar de un fundamento sólido a la pretensión moral de obediencia a la ley (y, en caso contrario, para justificar moralmente su desobediencia). Para ello es necesario que ésta sea expresión de la propia autonomía de los sujetos a los que se aplica y, por ello, legitimada por su aprobación, requisito que sólo puede satisfacerse concibiendo a la ley como expresión mediata o inmediata de la voluntad general. Sea directamente sea a través de la representación la ley aparece entonces como la expresión de la autonomía de un colectivo social que generaliza la autonomía de cada uno de sus componentes mediante el principio de mayorías ${ }^{8}$. La ley puede así, y sólo así, ser concebida como norma suprema en cuanto expresión de la potestad normativa última (la soberanía) que reside en el pueblo y puede entonces esgrimir un fundamento moral a su pretensión de obediencia. Esta «interpretación fuerte» me parece tener bastantes ventajas sobre la otra. En primer lugar porque es este imperativo ético el que ha sido satisfecho en la institucionalización contemporánea del poder legislativo como un poder democrático, es decir un poder que -aun con diversas variantes técnicas- siempre tiene en común, cuando es democrático, el haber sido elegido mediante elecciones libres y periódicas por lo cual detenta por delegación la soberanía misma ${ }^{9}$ y expresa, mediante leyes, la voluntad general.

${ }^{7}$ Dice Laporta: «Son, creo, los tres ideales que Elías Díaz ha pretendido englobar en uno solo mediante su noción amplia y ambiciosa de «Estado Democrático de Derecho»: imperio de la ley, pero ley entendida como expresión de la voluntad general, es decir, principio democrático, y ley que posibilite el reconocimiento formal y la realización efectiva de los derechos del hombre. Yo, por el contrario, prefiero proceder a aislar el primero de esos ideales, asumiendo que puede tener vida propia al margen de los otros y reflexionar únicamente sobre él.» (Laporta 1994, p. 138, subrayado mío).

${ }^{8}$ Precisamente sobre la fundamentación ética de la representación democrática, su relación con el principio de mayorías y la pretensión de obediencia de las reglas sociales así creadas es clarificador el artículo de Laporta (1989) Sobre la Teoría de la Democracia y el concepto de representación política: algunas propuestas para debate (en particular, pp. 139-140).

\footnotetext{
${ }^{9}$ En contra, como es sabido, Rousseau negaba precisamente que la soberanía pueda ser representada. «Digo, pues, que no siendo la soberanía sino el ejercicio de la voluntad general, no puede enajenarse jamás, y el soberano, que no es sino un ser colectivo, no puede ser representado más que por sí mismo... La soberanía no puede ser representada, por la misma razón que no puede ser enajenada; consiste esencialmente en la voluntad general, y ésta no puede ser representada: es ella misma o es otra; no hay término medio.» J. J. Rousseau 1762 (1968, p. 37 y p. 112).
} 
En segundo lugar porque los problemas que todavía están sobre la mesa se refieren a la universalización de la democracia, y ya no están sobre la mesa los problemas de justificar, frente al despotismo, la necesidad de un «orden jurídico» del Estado ${ }^{10}$. La tesis débil parece seguir defendiendo la superioridad moral de la legalidad frente a la arbitrariedad, lo cual no parece estar hoy en cuestión; la tesis fuerte parece seguir defendiendo la superioridad moral de la voluntad general (democracia) frente a cualquier forma de autoritarismo (tiranía u oligarquía), lo que todavía está, desgraciadamente, en cuestión.

Pues bien, esta idea de ley como norma que expresa la voluntad general es la versión clásica que recibimos de las formulaciones de Locke, Rousseau y Kant, y que alcanzó su primera realización en el modelo liberal de Estado, y es además la que aparece recogida en el Preámbulo de nuestra Constitución cuyo tercer párrafo señala -acogiendo la interpretación aquí llamada «fuerte»- que la nación española proclama su voluntad de «consolidar un Estado de Derecho que asegure el imperio de la ley como expresión de la voluntad popular». Y esta concepción parece implicar que la ley (en este sentido al que jurídicamente se denomina «formal» para distinguirla de otros sentidos del término «ley») goza de los siguientes caracteres: (1) la ley es única y, por ello, toda ley tiene la misma legitimación y la misma fuerza normativa (la denominada «fuerza de ley»); (2) la ley es la potencia normativa originaria, por cuanto es expresión de la voluntad normativa última que reside en los miembros del cuerpo social; (3) la ley es la máxima potencia creadora de Derecho y, por ello, la fuente suprema de creación de normas en un ordenamiento jurídico, a la que se encuentran sometidas cualesquiera otras fuentes como las costumbres, los principios o las decisiones judiciales; (4) la ley es incondicional en cuanto es soberana; su capacidad para regular la vida social y limitar la autonomía individual no está condicionada -como lo están las disposiciones reglamentarias- por su finalidad, porque la ley es autolimitación soberana de la autonomía individual. En resumen, la ley es la fuente única, originaria, suprema y omnipotente de creación del Derecho ${ }^{11}$.

\footnotetext{
${ }^{10}$ Locke, como antes Hobbes y después muchos otros, todavía tenía que preocuparse por exigir ese «orden jurídico»: «La autoridad suprema o poder legislativo no puede atribuirse la facultad de gobernar por decretos improvisados o arbitrarios: está, por el contrario, obligada a dispensar la justicia y a señalar los derechos de los súbditos mediante leyes fijas y promulgadas, aplicadas por jueces señalados y conocidos» (Locke 1690, Capítulo XI, \& 136).

${ }^{11}$ Vid. E, García de Enterría y T. R. Fernández 1990, I, pp. 135-137, donde se atribuyen a la ley, en cuanto «expresión de la voluntad popular» o «autodisposición de la comunidad sobre sí misma», los caracteres de irresistibilidad y supremacía, y se la define como «la única norma originaria que decide desde sí misma y por sí misma», si bien es cierto que considerando que Constitución y Ley son «dos rangos distintos dentro de la Ley». Vid. También L. M. Díez Picazo 1988, pp. 48-49 sobre los caracteres tradicionales de la ley.
} 
Algunas consecuencias relevantes de esta concepción han sido, en el modelo europeo, el sometimiento jerárquico de todas las demás fuentes y normas del ordenamiento a la ley, sometimiento cuyo control queda cuidadosamente encomendado a los Tribunales «Supremos» mediante el recurso de casación, así como la presunción de validez de las leyes que se manifiesta bien en una ausencia de control alguno de su validez, bien en un control especial y limitado encomendado a los Tribunales «Constitucionales» (en el esquema kelseniano). El modelo norteamericano, sin embargo, introdujo dos variantes que de algún modo suponen un debilitamiento de la supremacía de la ley: por una parte, la sanción presidencial que permite al propio poder ejecutivo (democráticamente legitimado por elección directa) devolver las leyes ya aprobadas por el Parlamento ${ }^{12}$ y la «judicial review», a la que más adelante haré referencia.

\section{Las crisis de la ley}

Conviene señalar aquí que esta concepción de la ley parece seguir predominando tanto en los trabajos de Filosofía y Teoría General del Derecho como en la Filosofía Política, a pesar de que ya hace bastante tiempo que esta concepción dista de dar cuenta adecuadamente de la realidad del ordenamiento jurídico. Este concepto de ley (que se utiliza hoy de forma habitual tanto descriptivamente como normativamente) viene, en efecto, sufriendo hace tiempo los envites de la propia realidad político-jurídica y, más recientemente, también de la teoría, de tal modo que se ha llegado a hablar, con motivos sobrados, de una auténtica «crisis de la ley» (L. Díez Picazo 1985, p. 9). Creo que tales motivos prácticos y teóricos pueden resumirse principalmente en cuatro: (1) la diversificación de la ley y la competencia entre los diversos tipos de leyes; (2) la aparición de normas no legales de carácter paralegal en los procesos de integración regional de los estados; (3) la expansión de la fuerza normativa de las constituciones; y (4) la expansión de la fuerza normativa de los principios.

\subsection{Diversificación de las leyes y competencia entre leyes}

Hay al menos tres motivos diferentes por los que se ha roto el carácter unitario de la ley, apareciendo en un mismo sistema jurídico diferentes tipos de leyes.

${ }^{12}$ El sistema de sanción presidencial está previsto en la Constitución de los Estados Unidos de América, Artículo I, Sección 7, párrafo 2) y se reproduce en términos similares en otras constituciones del continente. En particular, el Artículo 72, párrafos a), b) y c), de la Constitución Política de los Estados Unidos Mexicanos, donde se atribuye al Poder Ejecutivo (residenciado en el Presidente de los Estados Unidos Mexicanos por el Artículo 80) la facultad de desechar en todo o en parte un proyecto de ley o decreto del Congreso de la Unión, devolviéndolo con observaciones a la cámara de origen. En tal caso el proyecto requiere, para ser aprobado, dos tercios del total de votos en cada cámara. 
(1) La primera diversificación de leyes que cabe mencionar es la que se da en los ordenamientos correspondientes a lo que García Maynez llamaba «estados complejos» como lo son los estados federales. Es una diversificación que podemos denominar «horizontal». Obviamente es la diversificación más antigua y, en cierto sentido, menos problemática. Surge aquí una doble legislación: las leyes federales y las leyes estatales. Esta diversificación es hoy expansiva pues los ordenamientos simples (propios de los estados centralizados) se ven sometidos a procesos de descentralización política que suponen la aparición de entidades regionales que, como en España o en Italia, asumen cierto poder legislativo. La cuestión no es en absoluto nueva para el constitucionalismo y cualquier constitucionalista sabe que, generalmente, el conflicto entre leyes federales y leyes estatales (o -en el segundo caso- entre leyes del Estado y leyes autonómicas o regionales) debe plantearse y resolverse como un conflicto de competencia y no de jerarquía, salvando así -siquiera sea en primera instancia- el concepto unitario de ley. Es cierto, ello no obstante, que del criterio de competencia ha podido decirse con humor que es «un moderno talismán, muy empleado por los hombres de leyes para conjurar demonios normativos que escapan a la vieja razón jerárquica» (L. M. DíezPicazo 1989, p. 65). Pero no entraremos ahora en el aspecto técnico de esta cuestión ${ }^{13}$, sino que bastará señalar que si los constitucionalistas han podido reinterpretar en función del criterio de competencia las nociones de ley federal y ley estatal, y las relaciones y conflictos entre ellas, ha sido a costa de cerrar los ojos a la noción clásica de «soberanía», mientras que si los filósofos de la política y del Derecho han podido seguir hablando del concepto de soberanía ha sido a costa de cerrar los ojos a esta diversidad de leyes y de legisladores. Porque es claro que si el soberano es quien obtiene general obediencia y no obedece a nadie, difícilmente cabe concebir un soberano limitado. Es más, cabe explicar la autolimitación del soberano, bien sea desdoblando en el tiempo su decisión normativa autorreferente (N-t1) y las nuevas decisiones normativas que creará

${ }^{13}$ Sobre el aspecto técnico jurídico de la relación entre legislación estatal y legislación autonómica se ha producido, en España, una extensa literatura, en la que parece existir un acuerdo general respecto a que ambos tipos de leyes tienen el mismo rango jerárquico y que su diferenciación procede de la distinta competencia del respectivo legislador, criterio que opera limitando la competencia legislativa de las Comunidades Autónomas en un doble nivel, por razón de la materia y por razón del territorio (T. R. Fernández 1979, pp. 859). Por todos, López Guerra y otros 1991, p. 67: «Leyes del Estado y leyes de las Comunidades Autónomas poseen el mismo rango y fuerza, pero tienen acotado un campo material distinto determinado por el bloque de la constitucionalidad... Este criterio de separación entre ámbitos propios de las potestades normativas del Estado y de las Comunidades Autónomas se denomina principio de competencia...» Una tesis contraria a admitir que la Constitución atribuyera potestad legislativa a las Comunidades Autónomas fue sostenida, extensa e intensamente, por González Navarro (1979, pp. 1021-1157), tesis que no ha llegado a alcanzar éxito alguno. Otra tesis peculiar, también sin éxito, sostuvo Sánchez-Agesta (1979, p. 1907) al sugerir que las leyes de las Asambleas de las Comunidades Autónomas estaban jerárquicamente ordenadas en el nivel inferior a los reglamentos del Gobierno del Estado. 
dentro de los límites de aquélla (N-t2), bien sea mediante una descomposición jerárquica del propio concepto de soberano (soberano 0 y soberano 1) en la que el primero limita al segundo -como ha propuesto Ernesto Garzón ${ }^{14}$, en cuyo caso estamos realmente ante una heterolimitación vertical-, pero es una contradicción en los términos hablar de heterolimitación horizontal del soberano y, en un sistema complejo, el legislador estatal (o regional) no es un legislador autolimitado, sino un legislador heterolimitado por la competencia legislativa del poder federal (o del Estado), y el legislador federal (o del Estado) no es un legislador autolimitado sino heterolimitado por la competencia legislativa del poder estatal o regional; o bien -como parece más plausible- ambos son heterolimitados por el poder constituyente, en cuyo caso ninguno de los dos es soberano. Se puede argumentar que ello no quiebra el principio democrático último si la Constitución está democráticamente legitimada. Esto es cierto. Pero eso no niega que legislador estatal y legislador federal dejan de ser expresión incondicionada de una voluntad soberana.

(2) Un segundo motivo de diversificación legislativa viene originado -según afirman muchos autores- desde que «al Estado moderno se le pidieron más funciones de aquellas que tradicionalmente tenía» (L. Díez Picazo

${ }^{14}$ Como es sabido tanto Bodino como Austin sostuvieron que era conceptualmente imposible la limitación jurídica del soberano. Más recientemente Alf Ross suscitó el debate sobre la consistencia lógica de la norma que regula la reforma de una Constitución si se pretende que tal precepto regula, asimismo, su propia reforma, lo que condujo a la denominada «paradoja de Ross» (Ross 1969; aquí mismo puede verse [pp. 75-76] el argumento del desdoblamiento temporal, que Ross rechaza). Ernesto Garzón ha abordado el tema en un trabajo de obligada lectura (E. Garzón Valdés 1993, pp. 181-200, donde pueden encontrarse las referencias a Bodino y Austin), si bien la solución positiva que propone exige distinguir entre dos soberanos (soberano 0 y soberano 1), el primero de los cuales obedece a la definición de von Wright (aquél cuyo acto normativo de dictar una norma no es contenido de ninguna otra norma de un sistema) y el segundo de los cuales obedece a la definición de Bryce (la persona o grupo de personas a quienes la ley atribuye la capacidad de regular jurídicamente, en última instancia, la conducta social). Con esta convención Garzón resuelve las objeciones lógicas a la posibilidad de limitaciones legales al soberano, pero aceptar esta convención es aceptar, sencillamente, que la persona o grupo de personas a quienes habitualmente denominamos como soberano (soberano 1, o soberano en el sentido de Bryce) no son soberanos en el sentido de von Wright (soberano 0) que es el mismo sentido en que hablaban de soberano Bodino o Austin. Quiero decir que la propuesta de Garzón no resuelve la posibilidad de limitaciones jurídicas al soberano 0 (lo que él mismo reconoce expresamente [ibíd., p. 1971) sino que explica la posibilidad de limitaciones jurídicas a «otro» soberano, que es soberano en un sentido muy distinto. Y no se acaban de ver las ventajas de aceptar la convención propuesta por Garzón en lugar de, todavía más sencillamente, reconocer que el legislador (soberano 1) no es soberano, incluso que tampoco es soberano aquel que tiene potestad limitada para reformar una Constitución conforme a las reglas que la propia Constitución establece. O, todavía más: para reconocer que el concepto político de soberano -como el concepto jurídico de «norma fundamental» de Kelsen, o el concepto sociológico de «regla de reconocimiento» de Hart, o el concepto de No de Ross- son herramientas intelectuales para explicar el origen último, o el cambio revolucionario, de un sistema jurídico y que denotan, en todo caso, fenómenos externos al propio sistema. Lo que, a fin de cuentas, viene a dar la razón a Ross. 
1985, p. 11) con lo que empezó a surgir una desenfrenada actividad legislativa que incluye leyes medida (de carácter singular), leyes edicto (como las leyes de presupuestos), leyes programa (de carácter tecnocrático), leyes de habilitación al Gobierno, e incluso leyes puramente retóricas. De todas ellas se ha podido decir, con razón, que carecen de «un verdadero contenido normativo» (ibíd., p. 11). En la medida en que carecen de contenido normativo -y, en efecto, muchos de estos tipos carecen total o parcialmente de él- estas leyes son, en todo o en parte, expresiones de deseos o propósitos, decisiones de acción, o simples órdenes singulares y concretas de un órgano muy cualificado, el poder legislativo, pero no son normas propiamente hablando lo que es tanto como decir que no son leyes, en el sentido tradicional que estamos refiriendo.

Este segundo motivo es el que originó las primeras apelaciones a una «crisis de la ley» que se remontan a los años treinta ${ }^{15}$. El diagnóstico de la crisis reside en este aspecto en la pérdida del carácter general y abstracto de las leyes. La formulación más brillante del tema se encuentra, probablemente, en el conocido discurso rectoral de Otto Bachof de 1959 titulado «Jueces y Constitución»" ${ }^{16}$. El discurso podría resumirse -creo- en cuatro proposiciones encadenadas:

(a) Existe un Derecho anterior a las leyes (y a cualquier constitución positiva) del que las leyes eran «antes» expresión racional en cuanto reglas generales y abstractas (Bachof 1985, pp. $24,40,47$ y 50$)$

(b) Las leyes han dejado de ser expresión racional del Derecho en cuanto han dejado de ser reglas abstractas y generales, convirtiéndose en «actos de conformación política» mediatizados por la mayoría parlamentaria y los grupos partidistas que la dominan (ibíd., pp. 48, 49, 50, 51 y 52).

(c) Es necesaria una «fuerza» que restablezca los «valores superiores del Derecho» y la «paz jurídica», y esta fuerza «sólo puede ser el juez» (ibíd., pp. 47 y 54).

(d) El juez está sometido a la ley, pero no sólo a la ley; ni siquiera a la Constitución como ley de rango superior, pues existe la posibilidad, aunque lejana, de que una norma constitucional esté en contradicción con las ideas de justicia que preexisten a la Constitución. El juez, en última instancia, está sólo sometido a la soberanía del Derecho y al «imperio del Derecho» (ibíd., pp. 65 y 68).

El discurso de Bachof es, hoy, un discurso bastante extendido. Y conviene señalar que en él se ocultan dos afirmaciones, aparentemente progresistas, que le sitúan absolutamente al margen de los puntos de partida que caracterizan la «interpretación fuerte» del imperio de la ley. La primera consiste en la pretensión de que la validez moral de las leyes venía «antes»

${ }^{15}$ La más antigua obra de la que tengo referencia con el expresivo título de «La crisi della legge» es la de Carnelutti, en Discorsi intorno al Diritto, vol. I, CEDAM, Padua, 1937, que se cita en L. Prieto 1981, p. 100. nota 26.

${ }^{16}$ Fue publicado en castellano, en traducción de Rodrigo Bercovitz, en 1963 (Editorial Taurus) y reeditado en 1985 por Editorial Civitas. 
(cuando la ley era «escudo de la libertad y del Derecho» [ibíd., p. 48]) de su carácter de regla general y abstracta, no de su condición de expresar la voluntad general. La grandeza moral de la codificación liberal no proviene -al parecer- de la introducción, inicialmente limitada, del principio democrático, sino de la formulación en forma general y abstracta de los intereses de la burguesía. La segunda consiste en la pretensión de que el juez tiene la misma legitimidad democrática que el Parlamento y todos los demás órganos del Estado; la forma de designación es sólo una diferencia relativa puesto que -según se afirma- «más importante que la clase de mandato es la función desempeñada» (ibíd, p. 59). Estas dos afirmaciones, necesarias para mantener en pie un discurso como el de Bachof, suponen lisa y llanamente la destrucción del «Imperio de la ley» en nombre del «Imperio del Derecho».

(3) Un tercer motivo de diversificación -que, a diferencia del primero, podemos denominar «vertical»- reside, finalmente, en la técnica seguida por algunos ordenamientos -como el español- al establecer constitucionalmente diferentes categorías de leyes, como los Estatutos de Autonomía y las leyes orgánicas, que requieren procedimientos especiales y quórum especiales de aprobación ${ }^{17}$. Estas leyes se han considerado leyes interpuestas entre la Constitución y la legislación ordinaria, y todavía no es pacífica entre

${ }^{17}$ La Constitución Española distingue básicamente cinco tipos distintos de leyes (dejando al margen algunas peculiaridades relativas a las leyes de armonización, la ley de presupuestos, las leyes tributarias, las de emisión de deuda pública, etc. que no parecen afectar en absoluto a su rango jerárquico): (1) leyes orgánicas que aprueban Estatutos de Autonomía (Artículo 81, que se abre a dos procedimientos distintos de elaboración y aprobación del Estatuto según se aplique el Artículo 146 o el 151); (2) leyes orgánicas restantes (Artículo 81) cuya aprobación exige mayoría absoluta del Congreso en votación final de conjunto; (3) leyes ordinarias; (4) decretos legislativos y (5) decretos leyes.

Los decretos legislativos y los decretos leyes -como formas de legislación delegada en el Gobierno pero sometida al control del legislativo (mediante una ley aprobada previamente por las Cortes Generales para los decretos legislativos, y mediante la convalidación posterior por el Congreso para los decretos leyes)- no han suscitado problema alguno respecto a su rango de leyes ordinarias.

El problema se plantea respecto a los Estatutos de Autonomía y las restantes leyes orgánicas en relación con las leyes ordinarias. Las respuestas teóricas podrían ser tres: que se trata de tres niveles jerárquicos (Estatutos, leyes orgánicas, leyes ordinarias); que se trata de dos niveles jerárquicos (Estatutos y demás leyes orgánicas, leyes ordinarias); que se trata de un solo nivel jerárquico y que la distinción es sólo en virtud del criterio de competencia (legislador estatutario, legislador orgánico y legislador ordinario). Aunque algunos autores sostuvieron la diferencia jerárquica (por ejemplo, Díez Picazo 1979, p. 659; Garrido Falla 1979, p. 39; Sánchez Agesta 1979, p. 1907), la doctrina parece inclinarse mayoritariamente por la última solución (entre otros, Martín Oviedo 1979, p. 1280; Rubio Llorente y Aragón Reyes 1980, p. 848; García de Enterría y Fernández 1990, I, pp. 152-153; López Guerra y otros 1991, p. 69). No es necesario, a nuestros efectos, pronunciarse ahora sobre tan complicada cuestión. El lector interesado puede remitirse al estudio bibliográfico de F. J. Bastida Feijedo en el $\mathrm{n}^{\mathrm{o}} 2$ de la Revista Española de Derecho Constitucional (1981, pp. 285-311) o a la monografía de T. R. Fernández (Las leyes orgánicas y el bloque de la constitucionalidad, 1981). En todo caso ese punto de vista mayoritario -en favor del criterio de competencia ha sido sometido a una profunda y aguda crítica por L. M. Díez Picazo (1989). Desde la Filosofía del Derecho también L. Prieto había señalado, si bien respecto a las relaciones normas estatales-normas autonómicas, que «el principio de competencia es quizás un instrumento valioso para la interpretación jurídica, pero no un oráculo que resuelva sin más los problemas que plantea nuestro complejo sistema de fuentes.» (Prieto 1981, p. 126). 
nosotros la discusión entre quienes defienden que se trata de diferentes leyes sólo en virtud del criterio de competencia (lo que obliga a distinguir entre diferentes «legisladores»: el legislador orgánico, el legislador ordinario...) y quienes afirman que son leyes jerárquicamente superiores las unas, las orgánicas, a las otras, las ordinarias.

Las tres diversificaciones ponen en cuestión, como mínimo, que la ley sea un tipo único y originario y, en consecuencia, que exprese la voluntad de un -por definición, único en cada sistema- poder soberano. Constatar este triple fenómeno puede conducir, sin incurrir en exceso verbal alguno, a una conclusión como la formulada por Rubio Llorente (1986, pp. 99-100): «la idea de Estado de Derecho que informa la realidad jurídico-política española no identifica Estado de Derecho con «imperio de la ley». Lejos de postular la noción de soberanía parlamentaria, no es ni siquiera compatible con ella. La idea de Estado de Derecho hoy viva en España implica más bien la radical limitación del poder legislativo... lleva consigo, junto con un indudable debilitamiento de la ley como fuente del Derecho, una cierta necesidad de replantear la concepción misma de la ley...» ${ }^{18} \mathrm{Y}$, en efecto, el «imperio de la ley» parece debilitarse o, en el mejor de los casos, quedar sustituido por el imperio de la Constitución, o -lo que es más gravepor un difuso imperio del Derecho, salvo que podamos replantear nuestro concepto de ley y, al hacerlo, reivindicar sobre nuevas bases su imperio.

\subsection{Normas no legales de carácter paralegal}

En España se ha llegado a decir que, como consecuencia de la diversificación de tipos de leyes, nuestro sistema de fuentes es un «rompecabezas» o «una fonda inextricable» (respectivamente, L. M. Díez Picazo 1988, p. 91 y F. Rubio Llorente 1986, p. 111). Aun siendo así, este rompecabezas sería relativamente sencillo de resolver si no viniera a complicarse con otro nuevo factor: la integración en la Unión Europea. El proceso de integración europeo es, como es sabido, una forma más desarrollada y compleja de pertenencia a organismos internacionales de carácter político (como también lo son la Organización de las Naciones Unidas, la Organización de Estados Americanos, etc. $)^{19}$, que encuentra su origen en la constitución de un mercado común. De todo este complejo proceso, lo que ahora interesa señalar

18 Para Rubio Llorente esta conclusión deriva tanto del control jurisdiccional de la constitucionalidad de las leyes -al que luego haré referencia- como de la «profunda mutación en el concepto mismo de la ley... en el que se incluyen normas, que si bien proceden en todos los casos de órganos representativos, tienen muy diversas características jurídicas» -a lo que ahora me estoy refiriendo- (Rubio Llorente 1986, p. 83).

19 La Unión Europea es, sin duda, un proceso singular en este aspecto. «Jamás había sucedido -señala Capotorti- que en el ámbito de una organización internacional se hubiese adoptado en una medida tan amplia la 'transferencia de los poderes soberanos' de los Estados miembros, que viene a caracterizar a la realidad comunitaria» (Capotorti 1986, p. 249). 
es que la integración en el Mercado Común Europeo, hoy Unión Europea, supone la cesión de soberanía (o competencia) legislativa en ciertas materias a favor de los organismos competentes de la Unión. Nuevamente los hombres de leyes recurren al «talismán» del criterio de competencia para explicar las relaciones entre la legislación nacional y la normativa emanada de la autoridad comunitaria (Reglamentos y Directivas) ${ }^{20}$. Recurrir al criterio de competencia resuelve el problema pero no sólo a costa de cerrar los ojos a la noción de un legislador «soberano» sino en esta ocasión a la noción misma de legislador o ley. Y ello porque resulta que las normas comunitarias -que prevalecen sobre la legislación estatal cuando son de aplicación directa como lo son, al menos, los Reglamentos- no emanan de legislador alguno. El Parlamento Europeo, aun siendo hoy día de carácter electivo, carece de cualquier competencia legislativa y tanto los Reglamentos (nacidos del Consejo) como las Directivas (nacidas de la Comisión) son normas aprobadas por órganos no representativos (internacional el primero, ejecutivo no delegado de un legislativo el segundo) los cuales, sin necesidad de refrendo legislativo interno (como se exige para los Tratados Internacionales), prevalecen sobre la legislación nacional. ¿Cómo explicar ahora la posición de la ley? ¿Cuál es el sistema de fuentes en los ordenamientos cuyas leyes están sometidas a este peculiar normativa? ¿Cuál es la legitimación de estas normas no legisladas y, sin embargo, supra o paralegislativas? No pretendo responder ahora a estas preguntas. Como suele ocurrir los juristas positivos tienden a trabajar acríticamente sobre el material dado. Los filósofos y teóricos del Derecho, hoy por hoy, parecen preferir la ignorancia de estos fenómenos que ponen gravemente en cuestión nuestras más familiares concepciones del orden jurídico y su correspondiente aparato teórico ${ }^{21}$. Pero lo cierto es que no cabe ninguna explicación de este fenómeno

${ }^{20}$ Ha de señalarse que la utilización del criterio de competencia plantea, respecto a la relación derecho comunitario-derecho interno, nuevas complejidades ya que el sistema comunitario no establece un claro deslinde competencial entre los Estados y la Unión, de modo que cada Estado mantiene una competencia genérica sobre multitud de materias en tanto los órganos comunitarios no dicten disposiciones de desarrollo del Tratado. Cuando las dictan, estas disposiciones tienen un efecto derogatorio sobre la legislación interna que cabe explicar, desde luego, sin recurrir a un criterio jerárquico sino por el mero efecto de la «lex posterior». Cabe decir que la competencia comunitaria se asume en la medida en que se ejerce, pues una vez ejercida su efecto derogatorio se extiende también frente a la «lex posterior» nacional, tal y como declaró el Tribunal de Justicia en la Sentencia Simmenthal, del 9 de Marzo de 1978. De tal modo que el juez nacional puede y debe dejar de aplicar una ley nacional posterior si entiende que es contraria a una norma comunitaria aplicable, con lo cual la ley ha perdido la inmunidad frente al juez de la que goza incluso cuando es sospechosa de inconstitucionalidad. Se trata de una división competencial muy peculiar (ver F. Santaolalla 1979, p. 1931 sobre la imprecisión de la delimitación competencial entre el Derecho comunitario y el interno).

${ }^{21}$ Tiene particular interés, en mi opinión, un artículo inédito de J. C. Bayón en que se plantea la primacía del Derecho comunitario que, conforme a la doctrina sostenida en las Sentencias Van Gend en Loos y Costa c. Enel, se fundamenta en la autonomía del propio Derecho comunitario. Bayón llega a la conclusión de que tal primacía sólo puede apoyarse en los propios sistemas jurídicos internos (en pocas palabras: si una norma de S1 establece la primacía de S1 sobre S2 y una norma de S2 establece la primacía de S1 sobre S2, las normas de S1 prevalecen sobre las de S2, con arreglo a S2, en virtud de una norma de S2 [Bayón 1995, p. 16]) y de que el Derecho comunitario no constituye un sistema jurídico autónomo, aunque sí un sistema jurídico diferenciado (ibíd., p. 32) sobre la base de la existencia de prácticas de reconocimiento «parcialmente divergentes». 
desde el esquema conceptual de la ley que, con carácter normativo (lo que la ley debe ser), venimos manejando.

Cabe, desde luego, admitir que un poder soberano delegue parte de su soberanía en otro poder soberano más amplio, aun a costa de, en ejercicio de su soberanía, dejar de ser soberano. Esto es lo que ocurre en decisiones federativas puras como la que dio lugar a la Constitución de los Estados Unidos de América. En tal caso una comunidad política soberana se integra en una comunidad soberana mayor. Esta comunidad deja de ser soberana pero se convierte en parte de otra comunidad soberana en la que sus miembros mantienen la legitimidad para autoobligarse. Las leyes de la nueva comunidad (la Federación) continúan siendo expresión de la voluntad general. Pero es absolutamente distinto lo que ocurre si un poder soberano delega parte de su soberanía en un poder no soberano porque, de hacerlo así, quiebra el principio de legitimidad en que se basa. Paradójicamente ha sido un norteamericano, Bruce Ackerman, quien ha venido a señalar de forma rotunda la contradicción en los principios que esta situación implica: «Como Maastricht ha mostrado una vez más, los líderes políticos de Europa tienen ahora muy pocos incentivos para ceder grandes poderes de control al Parlamento Europeo. Por el contrario, la situación actual les promete el mejor de los mundos posibles. Por una parte, pueden escapar a la supervisión de sus parlamentos nacionales enfrentando a estas asambleas con hechos consumados elaborados por ellos mismos a nivel comunitario. Por otra, la debilidad del Parlamento Europeo deja las manos libres a los primeros ministros y presidentes nacionales para crear el derecho comunitario con sus socios a puertas cerradas.» (Ackerman 1995, p. 48).

No es fácil explicar con nuestro aparato conceptual habitual cuál es la posición del derecho comunitario en nuestros sistemas de fuentes del Derecho. Decir que en virtud de la aprobación del Tratado cada sistema jurídico entrega parte de su competencia normativa a las autoridades comunitarias competentes es relatar lo que ha ocurrido. Pero no explica las consecuencias que ello supone para el sistema de legalidad y, todavía mucho menos, las consecuencias sobre (o las contradicciones con) el sistema de legitimidad. La Constitución Española fue en este aspecto precavida, dada la inmediata perspectiva de adhesión: su Artículo 93 establece específicamente que «mediante ley orgánica se podrá autorizar la celebración de tratados por los 
que se atribuya a una organización o institución internacional el ejercicio de competencias derivadas de la Constitución.» ${ }^{22}$

Pero lo que aquí me interesa no son las complicaciones que la técnica de adhesión a la Unión Europea añade al sistema de fuentes sino algo bastante más sencillo de constatar y bastante más difícil de resolver. El sistema del Derecho comunitario implica una nueva y distinta quiebra del imperio de la ley como expresión de la voluntad general porque las normas comunitarias (Reglamentos y Directivas) cuya vigencia se impone desplazando, en su ámbito de competencia, las leyes internas de cada Estado no son «leyes» que emanen de ningún poder soberano o representativo de un soberano, no son expresión de ninguna «voluntad general».

\subsection{La expansión de la fuerza normativa de las Constituciones.}

La idea de que la Constitución es una norma jurídica vinculante o contiene normas jurídicas vinculantes, y no un mero programa (parte declarativa) y una norma de organización (parte normativa), debe remontarse sin duda alguna a la sentencia Marbury v. Madison en la que el juez Marshall, en 1803, decidió que correspondía a los Tribunales el control de la constitucionalidad de las leyes lo que implicaba asumir que la Constitución era una norma que, de forma efectiva, limitaba las competencias normativas del Congreso. Fuera del ámbito norteamericano -respecto al que debe recordarse que la doctrina Marshall levantó iniciales recelos y se fue imponiendo muy paulatinamente-, la idea de la normatividad directa de la Constitución tardó mucho en ser asumida. En ocasiones cuando fue asumida, como en el caso de México, lo fue de forma limitada a la protección directa en amparo de los derechos fundamentales. Hay que recordar que la concepción constitucional de Kelsen, y su creación de una jurisdicción constitucional concentrada (en la Constitución austriaca de 1920), que se generalizó tras la Segunda Guerra Mundial, supone una «división esquizofrénica» (L. M. Díez Picazo 1988, p. 72). Mientras la doctrina Marshall universaliza el carácter normativo de la Constitución permitiendo a cualquier órgano judicial la inaplicación de una ley que estime contraria a la Constitución (una simple aplicación del criterio jerárquico si la Constitución es una norma jurídica), la doctrina de Kelsen supone que la Constitución es, en efecto, una norma superior pero que los jueces ordinarios carecen de poder para inaplicar una

\footnotetext{
${ }^{22}$ Se ha señalado ya que el Artículo 93 de la Constitución, y la Ley Orgánica 10/1985, de 2 de Agosto, de Autorización para la Adhesión de España a las Comunidades Europeas, suponen una «autorruptura» constitucional. Alonso García (1986, p. 379) indica, en mi opinión con toda razón, que «el concepto de 'ruptura' constitucional implica la posibilidad de contradicción normativa con la Constitución... Un bloque o grupo normativo queda así salvaguardado en su constitucionalidad, aunque su lógica jurídica, los principios que lo informan y sus plasmaciones concretas se contradigan con el resto de los preceptos constitucionales.»
} 
ley por inconstitucional (es decir, para aplicar lisa y llanamente el criterio jerárquico que aplican habitualmente al resto del ordenamiento). Como en un inerte arrastre de la idea de la omnipotencia y supremacía del legislador soberano, las leyes aparecen -en la versión kelsenianadotadas de una especial presunción de validez que vincula al juez ordinario, aunque mediante procedimientos específicos y tasados la misma ley pueda ser declarada inconstitucional por un órgano jurisdiccional especial en aplicación del mismo criterio de jerarquía (y en demostración palpable de que la ley no es omnipotente ni suprema).

La ley que, como antes vimos, había dejado de ser un tipo de norma único y originario, deja ahora de ser un tipo de norma suprema y omnipotente, con lo que parece haber perdido no ya alguna sino todas las notas que la caracterizaban en nuestra clásica noción familiar. Ya no es suprema, porque recibe su validez de la Constitución y está jerárquicamente subordinada a ella; ya no es incondicional y omnipotente, porque está limitada por los principios y por los derechos subjetivos declarados por la Constitución. No obstante -suele argumentarse- la relación entre constitución y ley no es igual que la relación (generalmente más elaborada) entre ley y reglamento. El reglamento desarrolla la ley, pero la ley no desarrolla la Constitución, sino que simplemente está limitada por ella y, según los intérpretes más estrictos, sólo por los derechos fundamentales y por la distribución de competencias. Una ley es inconstitucional sólo si el legislador es incompetente en virtud de la diversificación de legisladores, o si limita el contenido esencial de un derecho fundamental.

Sin duda alguna la tarea interpretativa de los Tribunales Supremos y de los Tribunales Constitucionales ha sido, generalmente, trascendental para la consolidación del valor normativo de las constituciones y, particularmente, para la protección de los derechos fundamentales que quedaron así a salvaguarda no sólo de la acción de los gobiernos sino también de la acción de los legisladores. Pero, al hacerlo, al consolidar la fuerza normativa de las constituciones como norma única, originaria, suprema e incondicionada, se ha pagado el precio de privar a la ley de tales caracteres. Lo que nuestros clásicos llamaron «ley» parece ser hoy, en nuestros Estados de Derecho, la Constitución. Lo que hace pocos años llamábamos «imperio de la ley» parece ser hoy, en nuestros Estados de Derecho, el «imperio de la constitución». Y ello obliga a preguntarse: ¿Qué es la ley? ¿Qué queda, si queda algo, del «imperio de la ley»?

\subsection{La expansión de la fuerza normativa de los principios}

Principalmente ha sido Ronald Dworkin quien, como alternativa al debate iusnaturalismo-positivismo, ha ofrecido un nuevo modelo dinámico del 
ordenamiento jurídico en el que, junto a las reglas o normas en sentido estricto, se incluyen con una peculiar fuerza normativa los principios.

Los principios a los que Dworkin se refiere no coinciden con lo que, en sistemas jurídicos como el español, hemos considerado como «principios generales del Derecho», y a los que el Artículo 1 del Código Civil, siguiendo el modelo del Código Civil austriaco de 1811 y del italiano de 1865, atribuyó y sigue atribuyendo el carácter de tercera, subsidiaria y última fuente del Derecho. Son éstos principios implícitos en el ordenamiento de los que la mayor parte de la doctrina ha ofrecido una interpretación positivista; principios, por tanto, que se extraen de algunas normas constitucionales o legales o, en último extremo, de normas de carácter consuetudinario que expresan convicciones socialmente generalizadas (o generalizadas, al menos, en la comunidad jurídica). Los principios a los que Dworkin se refiere son, por el contrario, estándares muy generales que -según él- coexisten con las normas en un ordenamiento y se diferencian de ellas por razones lógicas (no actúan, como las normas, disyuntivamente) y porque tienen una dimensión de peso o importancia de la que carecen las normas. Los principios para Dworkin no son una fuente subsidiaria de la existencia de una regla formulada, sino otro elemento normativo que concurre con las reglas y se utiliza, como ellas, para justificar una decisión jurídica.

No ha sido fácil entender el alcance de la tesis de Dworkin. Para algunos autores los principios, en este sentido, son simplemente normas de una cierta especie, bien más fundamentales, bien más generales o bien más vagas. Otros autores, sin embargo, proponen que la distinción que hay que hacer entre principios y normas no es hermenéutica sino funcional (por eso -dicen- una misma norma puede funcionar a veces como regla y a veces como principio). La diferencia bajo este punto de vista reside en que una regla se aplica en forma de todo/nada, es decir, funciona como una razón excluyente, mientras que el principio es un mandato de optimización $^{23}$ que puede aplicarse o cumplirse en la forma de más/menos. Una regla en contradicción con otra o es válida y la desplaza o no es válida y queda desplazada. Un principio en contradicción con otro, puede ceder ante él pero no pierde su validez. Muchos autores, siguiendo la propia indicación de Dworkin (Dworkin 1984, pp. 146 y ss.), entienden que los principios actúan como justificación de la decisión sólo en los llamados «casos difíciles» esto

${ }^{23}$ Esta es la tesis de Robert Alexy. Atienza y Ruiz Manero (1996) han rechazado esta diferencia entre principios y reglas, considerando que los principios sólo se pueden cumplir en grados diversos cuando se trata de directrices o normas programáticas, pero no cuando se trata de principios en sentido estricto, como el principio de igualdad y no discriminación del Artículo 14 de la Constitución. A. Peczenick ha rechazado esta interpretación de Atienza y Ruiz, alegando que el Artículo 14 no es un principio, sino una regla, en el sentido de Alexy. Puede verse la crítica de Peczenick así como la contestación de Atienza y Ruiz Manero a ella (y a las de L. Prieto) en Doxa $n^{\circ}$ 12 (1992), pp. 327-352 (recogidas ahora en Atienza y Ruiz Manero 1996, Cap. I Apéndice). 
es «cuando un determinado litigio no se puede subsumir claramente en una norma jurídica, establecida previamente por alguna institución» (ibíd., p. 146), palabras que recuerdan muy literalmente el viejo mandato del antiguo Artículo 6 de nuestro Código Civil: «Cuando no haya ley exactamente aplicable al punto controvertido...» Si esta fuera la función de los principios, es decir actuar como fuente en defecto de ley (y de costumbre), la teoría de Dworkin no alteraría en nada nuestras convicciones tradicionales sobre el imperio de la ley. Y tampoco lo haría si añadimos que los principios actúan en todo caso, no sólo en los casos difíciles, como pautas de interpretación de las reglas, pues también esta función les atribuye el Artículo 1 de nuestro Código Civil. La tesis de Dworkin quedaría limitada a una discusión académica sobre si el positivismo explica adecuadamente la estructura y el funcionamiento de un ordenamiento que, como el nuestro y como casi todos, incluye de un modo o de otro a los principios como estándares de interpretación de las reglas y como fuente subsidiaria en defecto de regla explícitamente formulada.

Desafortunadamente la cosa no es tan sencilla ni en el propio Dworkin ni en un buen número de influyentes autores que consideran que hay algo más que extraer de la teoría de los principios. Entre nosotros, por ejemplo, Manuel Atienza y Juan Ruiz Manero afirman: «A veces se supone que los principios sólo entran en juego en el razonamiento justificativo de los órganos jurisdiccionales cuando éstos tienen que hacer frente a casos difíciles, pues en los casos fáciles las reglas son elementos necesarios y suficientes para justificar la decisión. Esta forma de ver las cosas no nos parece, sin embargo, aceptable, por lo siguiente. Un caso es fácil precisamente cuando la subsunción de unos determinados hechos bajo una determinada regla no resulta controvertible a la luz del sistema de principios que dotan de sentido a la institución o sistema normativo de que se trate.» (Atienza y Ruiz Manero 1996, p. 22). La conclusión que de aquí derivan es, naturalmente, que la obediencia del juez a las reglas exige previamente una deliberación sobre si el caso es fácil, es decir sobre si la regla supuestamente aplicable es conforme con los principios y ello tanto si se trata de «valores» -en cuyo caso hay que deliberar si la regla los realiza- como si se trata de «objetivos» -en cuyo caso hay que deliberar si la regla es el medio adecuado- (ibíd.).

Robert Alexy ha reconocido expresamente que «la teoría de los principios ofrece un punto de partida adecuado para atacar la tesis positivista de la separación entre Derecho y moral» (Alexy 1988, p. 144), esto es que viene a reunificar la moral con el Derecho. Luis Prieto ha sido todavía más explícito al extraer las consecuencias: «En el planteamiento de Dworkin se trata de sostener, sencillamente, que algunas normas llamadas principios forman parte del Derecho porque son justas, aun cuando ningún legislador o juez las haya tenido en cuenta, incluso aun cuando la comunidad social las ha ignorado hasta el presente. Con lo cual la teoría de los principios -al menos, la de Dworkin- recobra otra vieja característica que tuvo en sus orígenes 
y que explica la cautela con que siempre fue vista por el positivismo; esto es, que los principios se quieran convertir en el vehículo o plasmación de un presunto Derecho Natural» (Prieto 1994, p. 198). ${ }^{24}$

En todo caso la tesis de Dworkin se ha extendido de tal modo que muchos autores, dando un muy discutible paso desde la mera descripción de cómo opera la argumentación jurídica a la justificación de cómo debe operar, sostienen un modelo de aplicación judicial del Derecho que autoriza y requiere al juez para que, antes de aplicar una norma (incluso legal), sopese la conformidad de la norma con los principios pues no basta -dicen- con que la decisión judicial esté jurídicamente fundada, sino que es necesario que sea moralmente consistente o -en formulaciones más matizadas- no basta con que la decisión judicial esté fundada en la norma, sino que es necesario que sea consistente con el «sistema de principios» ${ }^{25}$.

Si tenemos en cuenta que las constituciones, por su propio carácter, contienen una gran cantidad de principios en cualquiera de los sentidos que se den a este término, esto es: de normas muy generales, de normas muy vagas, de normas programáticas, de normas que expresan valores superiores del ordenamiento, de normas dirigidas a los órganos de aplicación e incluso de «regulae iuris» (como el principio de jerarquía normativa o el principio de irretroactividad) (Atienza y Ruiz Manero 1996, pp. 3-4, donde ofrecen estos seis tipos de principios); si asumimos la indiscutible fuerza normativa de las constituciones-, y si añadimos a ello la expansiva fuerza normativa de los principios, será obligado concluir que las leyes corren el riesgo de perder toda «perentoriedad» normativa, esto es todo su imperio, para ceder paso al imperio del intérprete ${ }^{26}$.

La invocación expansiva de los principios, en la forma que hemos visto, tiende aparentemente a elevar la moralidad del Derecho -y digo aparentemente porque presupone una racionalidad y una pureza en los órganos de

\footnotetext{
${ }^{24}$ Más extensamente en L. Prieto, Sobre principios y normas. Problemas del razonamiento jurídico, Centro de Estudios Constitucionales, Madrid, 1992.

25 En España esta posición está cualificadamente representada por Atienza y Ruiz Manero (1996, pp. 22-24), que sostienen que la deliberación judicial es una deliberación «normativamente guiada» en la que, si bien las razones relevantes son las contenidas «en el propio Derecho» como principios explícitos o implícitos, lo cierto es que supone en todo caso (como paso previo para decidir si el caso es fácil o difícil) ponderar las reglas con los principios, de tal modo que «la dimensión de obediencia a razones perentorias ya no puede aparecer como primaria» (ibíd., p. 23).

Atienza y Ruiz Manero señalan allí mismo (p. 19) que «la importancia de los principios en los ordenamientos jurídicos -como se ha observado muchas veces- corre paralela a la progresiva judicialización del Derecho».
}

${ }^{26}$ L. Díez Picazo (1985, p. 22) concluye que «la extensión desorbitada de la técnica de aplicación directa de la Constitución está(n) produciendo entre nosotros una potenciación extraordinaria del Derecho judicial». Compárese esta conclusión con la referida en la nota anterior, que conduce a idéntica conclusión respecto a la fuerza normativa de los principios. 
aplicación tan grande o mayor que la otrora atribuida al legislador- pero lo hace, desde luego, a costa del «imperio de la ley».

\section{En defensa del imperio de la ley}

Mi propósito ha sido, hasta aquí, mostrar que el concepto de «imperio de la ley», en su formulación clásica que en 1966 recogió Elías Díaz (y que luego ha sido recogida por el Preámbulo de nuestra Constitución), resulta hoy problemático. Pero creo que los cuatro tipos de problemas que he señalado no conducen necesariamente a desechar el imperio de la ley, y el consecuente principio de legalidad, aunque sí exigen su reformulación. Partimos de dos concepciones, ambas normativas, del imperio de la ley: una débil y otra fuerte. Ambas se ven afectadas con diferente intensidad por los cuatro factores que he analizado. La concepción débil, lógicamente, en mucha menor medida por cuanto es menos exigente ${ }^{27}$.

(1) La diversificación de tipos de leyes en nada afecta a la concepción débil siempre y cuando los tipos de leyes reconocidos en un sistema dado cumplan los requisitos genéricos de estructura de las normas y se relacionen entre ellas conforme a criterios de competencia o jerarquía claros públicos y prospectivos. Afecta, sin embargo, a la concepción fuerte (el imperio de la ley como expresión de la voluntad general) en cuanto aparentemente quiebra la noción de que la ley es única y suprema. Deja de ser única porque hay diferentes tipos de leyes y deja de ser suprema en cuanto algunas de ellas son superiores a las otras (en la diversificación horizontal) o todas ellas están por debajo de la norma que divide la competencia (en la diversificación horizontal). Pero esto sólo afecta a una noción de ley que tuvo predicamento ante una realidad jurídica -la del Estado liberal de Derecho en su forma continental- más simple que la actual. La suposición de que el concepto de ley y de su imperio implica un único tipo de ley era una constatación derivada de cómo era la estructura de los sistemas jurídicos modernos tras la consolidación delEstado-nación. Pero no hay, en la idea de ley como expresión de la voluntad general, ninguna implicación necesaria de que la ley constituya un tipo único, o un grado jerárquico único. Lo que tienen en común diversos tipos de normas como la Constitución, las leyes orgánicas, las ordinarias, las autonómicas, las estatales o las federales, es su peculiar autor y su peculiar procedimiento de decisión, que exige una discusión abierta entre representantes de los electores (o entre ellos mismos, en el caso de un referéndum) y una decisión por mayoría. Es esta doble peculiaridad, el carácter directamente representativo y plural del órgano competente y el procedimiento deliberativo lo que define a la ley como expresión

${ }^{27}$ No parece necesario insistir en que ambas concepciones son distintas pero no se contradicen. La concepción fuerte asume, en todo caso, el «universo ético» de la concepción débil. 
de la voluntad popular y, en este sentido, la pluralidad de manifestaciones de la voluntad popular en nada afecta al carácter de la ley, a su legitimidad y a su pretensión moral de obediencia.

(2) La aparición de normas no legales de carácter paralegal tampoco parece afectar en absoluto a la concepción débil. Las normas comunitarias, sean cuales sean las dificultades para dar cuenta del sistema de fuentes resultante en los derechos internos, parecen reunir los requisitos que la concepción débil exige de las normas. Sin embargo constituyen una quiebra total de la concepción fuerte. No se trata en este caso de que obliguen a cambiar o corregir algún elemento de nuestro concepto normativo de ley, se trata de que no le satisfacen en absoluto. Y ello no parece ser un problema conceptual si no un urgente problema real. De modo que la concepción fuerte no deja alternativa: o reivindicamos la democratización de la Unión Europea o hacemos dejación de nuestra concepción moral del imperio de la ley. Lo único que cabe decir es que la realidad jurídica no corre, ni nunca ha corrido, pareja con su deseable legitimidad. El Derecho comunitario es, en este aspecto, necesariamente perfectible y, lo que es más grave, urgentemente perfectible. Su reconversión, su maduración, en términos de imperio de la ley no es sólo algo deseable, es algo necesario si quiere merecer nuestro respeto.

(3) La supremacía de la Constitución, y su expansiva fuerza normativa, tampoco afecta a la concepción débil por las mismas razones indicadas en (1). Sí parece, sin embargo, poner en crisis aquellos otros tres rasgos tradicionalmente asociados a la concepción fuerte del imperio de la ley (su carácter originario, supremo e incondicional). Pero de nuevo habría que señalar que tales rasgos son contingentes para este concepto. El mismo Locke (1690, Capítulo XI, § 135) sostenía que el poder legislativo supremo, «a pesar de que sea el supremo poder de cualquier Estado,» está sometido a restricciones pues no puede ser superior al poder que los miembros de la sociedad tenían en estado de naturaleza. Como ha señalado García Pelayo (1980, p. 52), «para la idea original del Estado de Derecho non voluntas, sed ratio facit legem. Por consiguiente, si bien la legalidad es un componente de la idea del Estado de Derecho, no es menos cierto que éste no se identifica con cualquier legalidad, sino con una legalidad de determinado contenido, con una legalidad que no lesione ciertos valores y para los cuales se constituye el orden jurídico y político y que se expresan en unas normas o principios que la ley no puede violar» ${ }^{28}$. En realidad los rasgos de originariedad,

${ }^{28}$ En este mismo sentido J. C. Bayón ha señalado recientemente (1996, p. 7) que «sin duda puede afirmarse, y desde luego se ha hecho, que el ideal del Estado de Derecho encierra más cosas que este concepto de imperio o supremacía de la ley: que también exige al legislador cierta forma específica de legitimidad de origen (democrática) e incluso cierta forma específica de legitimidad de ejercicio.» Con ello entiendo que delimita lo que aquí defiendo como concepción fuerte, lo que lleva aparejado en efecto tanto una determinada legitimidad de origen de la ley, como una concepción normativamente limitada de la potencia de la ley (limitada por los requerimientos de legitimidad en ejercicio que básicamente se traducen en el respeto a los derechos básicos). 
supremacía e incondicionalidad corresponden más a los intentos de explicar la posición de la ley en la estructura del sistema normativo que a la concepción moral (normativa) del imperio de la ley. En el terreno explicativo es obvio que tales rasgos -por otra parte discutidos y discutiblesse trasladan a la Constitución. La forma última en sentido jerárquico en que la voluntad general se expresa es la Constitución, y la Constitución es bien definida como primera instancia de poder legislativo ${ }^{29}$. Es necesario, por otra parte, romper la ecuación entre ley (o constitución) y soberanía, porque el concepto de soberanía es una vaporosa imagen de una forma política periclitada. Lo que nos importa es que las leyes sean expresión de la voluntad general y, por ello, que en cada escalón de la constitución o desenvolvimiento de las comunidades políticas, las decisiones normativas estén originariamente legitimadas democráticamente. Una soberanía escalonada sigue siendo un ejercicio colectivo de la libertad negativa mediante las técnicas de instrumentación de la libertad positiva. Una Constitución es un momento del pacto social, pero un momento muy limitado, y el pacto social sólo puede ser una realidad actuante en la medida en que se actualiza mediante la legislación.

(4) La fuerza expansiva de los principios, que como hemos visto actúa unida a la expansiva normatividad de las Constituciones, sí parece plantear problemas a ambas concepciones del imperio de la ley. A la concepción débil en la medida en que, como se reconoce expresamente, supone una progresiva judicialización del Derecho y, con ello, un debilitamiento de la función de aplicar reglas en favor de aplicar razones ${ }^{30}$. Más todavía, quiebra los requerimientos de la concepción fuerte cuando sitúa al juez por encima de toda «perentoriedad normativa». Porque el juez, o cualquier otro funcionario, a quien corresponda el rol de aplicar las normas de un sistema dado, no tiene otra legitimación que aquélla que tengan las normas (sean éstas normas-regla o normas-principio) de ese sistema. Su legitimidad no proviene de la representación, sino de la función. Pero la función, contra lo que Bachof dijo, no es ni ajena ni alternativa, ni mucho menos superior, al título. La única legitimidad del juez es la propia legitimidad del sistema del que es operador cualificado e, inevitablemente, en algún grado creador. Por lo tanto la única legitimidad del juez democrático es aplicar las leyes -y los principios- del sistema democrático. Y ello exige un «principio fuerte de deferencia» (Bayón 1996, p. 31) del juez ante la ley.

${ }^{29}$ E. Díaz (1995, p. 9): «División de poderes, legislativo, ejecutivo y judicial, con lógico predominio en última y más radical instancia del poder legislativo, primero constitucional y luego parlamentario...»

${ }^{30}$ Vid. J. C. Bayón 1996, p. 24: «el ideal clásico del imperio de la ley requiere un derecho de reglas, por cuanto un derecho de principios daría lugar a un modelo de jurisdicción sobre la pauta de la 'jurisprudencia de razones' que frustraría el propósito primario de servir de condición de posibilidad de la autonomía individual.» 
Posiblemente la legislación es hoy deficitaria, si es que alguna vez no lo ha sido, en calidad. Posiblemente el legislador democrático es un muy imperfecto espejo de una comunidad ideal de decisión racional. Pero el legislador democrático, y sus leyes, son hoy por hoy -y mientras no se demuestra lo contrario- no sólo el menos malo de los sistemas posibles de decisión colectiva, sino -sin duda alguna- el mejor de todos los conocidos. Y cuando la ley es expresión de la voluntad popular su imperio constituye el primer imperativo de la moral colectiva.

\section{REFERENCIAS BIBLIOGRÁFICAS}

Ackerman, Bruce (1995) El futuro de la revolución liberal, Ariel, Barcelona.

Alonso García, Enrique (1986) La incidencia en el ordenamiento constitucional español de la Ley orgánica 10/1985, de 2 de Agosto, de autorización para la adhesión de España a las Comunidades Europeas, como puesta en práctica del Artículo 93 de la Constitución española, en García de Enterría y otros 1986, pp. 355-384.

Atienza, Manuel y Ruiz Manero, Juan (1991) Sobre principios y reglas, Doxa nº 10, pp. 101-120.

-(1996) Las piezas del Derecho. Teoría de los enunciados jurídicos, Ariel, Barcelona.

Bastida Feijedo, F. J. (1981) Comentario bibliográfico sobre la naturaleza jurídica de las leyes orgánicas, Revista Española de Derecho Constitucional, no 2, Mayo-Agosto 1981, pp. 285-311.

Bayón, J. Carlos (1993) Integración europea e identidad de los sistemas jurídicos, inédito.

-(1996) Principios y reglas: legislación y jurisdicción en el Estado constitucional, inédito.

Capotorti, Francesco (1986) El procedimiento de producción legislativa en las Comunidades Europeas, Revista Española de Derecho Constitucional, no 16, Enero-Abril 1986, pp. 247-285.

Díaz, Elías (1966) Estado de Derecho y sociedad democrática, Cuadernos para el Diálogo, Madrid (se cita por la edición de 1973).

-(1995) Estado de Derecho: exigencias internas, dimensiones sociales, Sistema no 125, Marzo 1995, pp. 5-22.

Díez Picazo, Luis (1979) Constitución y Fuentes de Derecho, en Varios 1979, pp. 649-665.

-(1985) Constitución, Ley, Juez, Revista Española de Derecho Constitucional, $\mathrm{n}^{\mathrm{o}}$ 15, Septiembre-Diciembre 1985, pp. 9-23.

Díez Picazo, Luis María (1988) Concepto de Ley y tipos de leyes, Revista Española de Derecho Constitucional, $\mathrm{n}^{\circ}$ 24, Septiembre-Diciembre 1988, pp. 47-93.

-(1989) Ley autonómica y Ley estatal (Sobre el significado del principio de competencia en el Estado autonómico), Revista Española de Derecho Constitucional, no 25, Enero-Abril 1989, pp. 63-86.

Fernández, Tomás Ramón (1979) Autonomía y Sistema de fuentes, en Varios 1979, pp. 823-886.

-(1981) Las leyes orgánicas y el bloque de la constitucionalidad, Cuadernos Civitas, Madrid. 
García de Enterría, Eduardo y otros (1986) Tratado de Derecho comunitario europeo (Estudio sistemático desde el Derecho español), tres tomos, Civitas, Madrid.

García de Enterría, Eduardo y Fernández, Tomás Ramón (1990) Curso de Derecho Administrativo I,

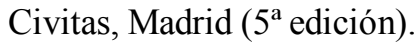

García Pelayo, Manuel (1980) Las transformaciones del Estado contemporáneo, Alianza, Madrid.

Garrido Falla, Fernando (1979) Las fuentes del Derecho en la Constitución española, en Varios 1979, pp. 27-48.

Garzón Valdés, Ernesto (1993) Derecho, Ética, Política, Centro de Estudios Constitucionales, Madrid.

Gondra Romero, José M. (1986) Integración económica e integración jurídica en el marco de la Comunidad Económica Europea, en García de Enterría y otros 1986, pp. 275-312.

González Navarro, Francisco (1979) Potestad legislativa del Estado y potestad reglamentaria autónoma de las nacionalidades y regiones, en Varios 1979, pp. 1021-1157.

Kant, Emmanuel (1797) (1978) Introducción a la Teoría del Derecho, Centro de Estudios Constitucionales, Madrid.

Laporta, Francisco (1994) Imperio de la Ley. Reflexiones sobre un punto de partida de Elías Díaz, Doxa $\mathrm{n}^{\mathrm{o}}$ 15-16, Vol. 1, pp. 133-145.

López Guerra, Luis y otros (1991) Derecho Constitucional, Vol. I, Tirant Lo Blanch, Valencia.

Martín Oviedo, José M. (1979) Tipología, jerarquía y producción de las normas en la Constitución española, en Varios 1979, 1275-1306.

Peces Barba, Gregorio (1981) La Constitución española de 1978. Un estudio de Derecho y Política, Fernando Torres, Valencia.

Pizzorusso, Alessandro (1984) Lecciones de Derecho Constitucional, dos tomos, Centro de Estudios Constitucionales, Madrid.

Predieri, Alberto y García de Enterría, Eduardo (1980) La Constitución española de 1978. Estudio sistemático, Civitas, Madrid.

Prieto Sanchís, Luis (1981) El ordenamiento jurídico en la Constitución, en Peces Barba 1981, pp. 93-156.

Rousseau, Juan Jacobo (1762) (1968) Contrato Social, Espasa Calpe, Madrid.

Ross, Alf (1969) El concepto de validez y otros ensayos, Centro Editor de América Latina, Buenos Aires.

Rubio Llorente, Francisco (1986) El procedimiento legislativo en España. El lugar de la ley entre las fuentes del Derecho, Revista Española de Derecho Constitucional, n 16, Enero-Abril 1986, pp. 83-113.

Rubio Llorente, Francisco y Aragón Reyes, Manuel (1980) La jurisdicción constitucional, en Predieri y García de Enterría 1980, pp. 829-886.

Sánchez-Agesta, Luis (1979) La jerarquía normativa en la Constitución de 1978, en Varios 1979, pp. 1895-1908.

Santaolalla López, Fernando (1979) Los tratados como fuente del Derecho en la Constitución, en Varios 1979, pp. 1907-1938.

Varios (1979) La Constitución española y las fuentes del Derecho, tres tomos, Dirección General de lo Contencioso del Estado. Instituto de Estudios Fiscales, Madrid. 